\title{
AURA, REPRODUÇÃO TÉCNICA E RISCO DE BARBÁRIE: REFLEXÕES BENJAMINIANAS
}

Pablo Tahim Pereira Silva

\begin{abstract}
RESUMO
Uma sociedade arrasada pelos horrores promovidos pela Primeira Guerra Mundial e uma Alemanha arruinada economicamente perante as outras nações se constituem um ambiente propicio para o surgimento de líderes que se apresentam como redentores de uma sociedade fadada ao fracasso. Daí certas propostas estimulariam a valorização de um nacionalismo exacerbado, de uma moral e de certa ideia de 'pureza' de um povo 'escolhido': fundamentais para o reestabelecimento do orgulho de uma nação. Em meio a tal conjuntura política, Benjamin observa a presença de uma crescente manipulação da humanidade com a utilização dos meios culturais por parte de regimes totalitários como o fascismo. O objetivo deste artigo, é apresentar como a técnica estaria sendo expropriada de sua função politizadora para a sociedade, e por conseguinte, sendo utilizada para a sua manipulação ideológica. A arte de propaganda, o culto à personalidade, seriam formas, segundo Benjamin, de estetização da política em uma sociedade cada vez mais estandardizada e alienada.
\end{abstract}

\section{AURA, TECHNICAL REPRODUCTION AND RISK OF BARBARITY: BENJAMINIAN REFLECTIONS}

\begin{abstract}
A society that had been destroyed by the horrors of the First World War and Germany that was, in comparison to the other nations, economically collapsed represented the perfect framework for the emergence of a specific kind of leaders: men who thought of themselves as redeemers of a society that was fated to collapse. In those circunstances some suggestions caused the enhancement of an exacerbate nationalism, of a moral and of an idea of "purity" of the "chosen" population: these beliefs were essential to restore the nation's pride. Amid these politics, Benjamin acknowledges the presence of an increasing manipulation of humanity through cultural resources by totalitarian regimes, like Fascism. The purpose of this article is showing how the technique was being expropriated of its political function to be used on society, and consequently how it was being used for ideological manipulation. According to Benjamin the art of propaganda and the cult of personality were ways of aestheticizing politics in a society that was getting more and more standardised and alienated.
\end{abstract}


Na época de Homero, a humanidade oferecia-se em espetáculo aos deuses olímpico; agora, ela se transforma em espetáculo para si mesma. Benjamin

Nem a todos é dado tomar um banho de multidão: fruir a multidão é uma arte; e só aquele a quem uma fada insuflou no berço o gosto e o disfarce, o ódio do domicílio e a paixão da viagem, só ele conseguirá à custa da multidão, tomar uma barrigada de vitalidade. Multidão, solidão: termos iguais e convertíveis para o poeta activo e fecundo. Quem não saiba povoar sua solidão, também não saberá estar só meio da multidão afadigada. Baudelaire

\section{Reelaboração dos temas e conceitos da pequena história da fotografia: a}

\section{aura na obra de arte}

Com o processo de popularização da fotografia, Benjamin atesta uma democratização no acesso ao conteúdo artístico e, além disso, na possibilidade de qualquer pessoa poder se apropriar dessa nova forma de arte. Com o advento do cinema, Benjamin percebeu ser necessária a adequação de alguns conceitos abordados no ensaio Pequena história da fotografia ${ }^{1}$. Ainda se discutia sobre a função artística da fotografia e do cinema, porém, com a massificação deste último, uma nova forma de apropriação do conteúdo artístico estaria surgindo. Em relação à fotografia, havia um problema quanto ao seu surgimento, pois ainda havia uma mística envolvendo sua existência. Com o cinema, os homens passavam a se apropriar de uma maneira ampla de vários modos de percepção artística, cultural e política. Perscrutando esse fenômeno, Benjamin busca justificar o potencial críticoreflexivo que o cinema poderia exercer na sociedade (BENJAMIN, 1985, 174).

Havia uma discussão intensa sobre o caráter da fotografia, se de fato seria uma forma de arte ou não. ${ }^{2}$ Segundo Benjamin, houve um período de transição da

1 Ao iniciar o percurso sobre a história da fotografia no ensaio Uma pequena história da fotografia, Walter Benjamin pretende apresentar para o leitor um histórico da evolução da fotografia, a partir do seu surgimento na Modernidade. Não obstante a presença no autor de uma busca em percorrer historicamente o desenvolvimento da técnica fotográfica, desde a sua invenção por Louis Daguerre, em meados do século XIX, ele pretende, nesse ensaio, ir além de uma simples abordagem histórica. A tentativa de Benjamin é a de demonstrar como a fotografia, desde os seus primórdios, e durante o seu desenvolvimento, possuiu um papel fundamental nas mudanças das relações sociais presentes na Modernidade.

2 Segundo Benjamin, "No máximo o próprio artista divino, movido por uma inspiração celeste, poderia atrever-se a reproduzir esses traços ao mesmo tempo divino e humano, num momento de extrema solenidade, obedecendo às diretrizes superiores do seu gênio, e sem qualquer artifício mecânico. Aqui aparece, com todo o peso de sua nulidade, o conceito filisteu de arte, alheio a qualquer consideração técnica e que pressente seu próprio fim no advento provocativo da nova técnica. $E$, no entanto, foi com esse conceito fetichista de arte, fundamentalmente antitécnico, que se debateram os teóricos da fotografia durante quase cem anos, naturalmente sem chegar a

Professor de Filosofia do ensino básico nos Colégio Teleyos e Colégio Ateneu. Brasileiro, residente em Fortaleza - CE. Email: pablo tahim@hotmail.com 
arte, que envolveu a fotografia e o cinema. Com o advento dessas novas técnicas, ocorreu uma refuncionalização da arte, onde a autonomia artística se perdia na emancipação dos seus fundamentos de culto (BENJAMIN, 1985, 176). Na seção Fotografia e cinema como arte no ensaio $A$ obra de arte na era de sua reprodutibilidade técnica, Benjamin retoma o problema enfrentado pela fotografia, na questão do seu reconhecimento como forma de arte: Benjamin demonstrar que também o cinema (sob formas mais complexas, mas com a mesma superficialidade), como a fotografia, também sofrera com esse mesmo problema de reconhecimento enquanto arte no período do seu advento. Não obstante a necessidade de se conferir à fotografia - e posteriormente ao cinema - uma valoração artística por meio da inserção de elementos como a pintura, tentou-se reestabelecer o valor cultual (Kultwert) que estaria se perdendo. Segundo observa Benjamin:

É revelador como o esforço de conferir ao cinema a dignidade de "arte", com inexcedível brutalidade, a introduzir na obra elementos vinculados ao culto. (...) É típico que ainda hoje, autores especialmente reacionários busquem na mesma direção o significado do filme e vejam, senão na esfera do agrado, pelo menos na do sobrenatural (BENJAMIN, 1985, 177).

Benjamin observa na fotografia um último respiro da aura. Diante da apropriação do rosto humano como um tema das primeiras fotografias, Benjamin reconhece uma última tentativa de manutenção do valor de eternidade. Em $\mathrm{Na}$ exposição universal de 1855, ocorreu a primeira exibição fotográfica. Pôde-se observar um paradoxo, no que diz respeito à questão do valor de exposição, a proximidade e o valor de culto. Ao mesmo tempo em que a fotografia demonstrava um caráter de secularização da arte, mantinha elementos que remetiam ao seu caráter ritual, a manutenção de uma aura. A insistência na valoração ritual encontrava-se na constituição dos modelos fotográficos, em torno dos retratos.

O público inundava as exibições, detendo-se ante inumeráveis retratos de personalidades famosas e celebradas, e pode-se imaginar o que isso significava nessa época em que se podia ver famosos personagens de teatro, perdendo a vida no pódio que até então, era o lugar onde estes se entreviam de longe.(BUCK-MORSS, 2002, 171)

nenhum resultado". Nesse sentido, ver: BENJAMIN, Walter. Uma Pequena história da fotografia p.92

Professor de Filosofia do ensino básico nos Colégio Teleyos e Colégio Ateneu. Brasileiro, residente em Fortaleza - CE. Email: pablo tahim@hotmail.com 
Como Benjamin sustenta, a arte nos tempos antigos possuía uma espécie de invólucro ${ }^{3}$ - marca pela tradição. Na sequência do ensaio, ele explicitará a sua concepção de aura, já iniciado no ensaio Uma pequena história da fotografia, ao expor o aspecto de singularidade que existia no conteúdo artístico. Daí Benjamim indagar:

\begin{abstract}
Em suma? O que é a aura? É uma figura singular composta de elementos espaciais e temporais: a aparição única de uma coisa distante, por mais perto que ela esteja. Observar em repouso, numa tarde de verão, uma cadeia de montanhas no horizonte, ou um galho, que projeta sua sombra sobre nós, significa respirar a aura dessas montanhas, desse galho. (BUCKMORSS, 2002, 170).
\end{abstract}

Para Benjamin, a obra de arte sempre esteve envolta de uma sacralidade, de certo caráter mágico e ritual, devido ao fato de ter assumido um valo hierárquico, no reduto de templos e palácios, fenômeno desconhecido da antiguidade clássica grega, onde os objetos de arte estão espalhados em praças com o acesso a todos. Nessa condição de acesso restrito ela se manteve distante das massas, estando à disposição apenas de um grupo seleto de espectadores, que a revestia de um valor quase teológico. Sobre essa roupagem teológica, Taísa Palhares explicita:

\begin{abstract}
A tradição valoriza na obra a unicidade e a autenticidade, sendo que elas não representam nada mais do que sua aura. Ocorre que essa sua valorização do objeto único, não é senão a lembrança da forma mais primitiva de incorporação da arte na sociedade, a saber, como culto e cuja função qualifica de ritual. [...] Consequentemente, toda e qualquer tradição que dê valor essencial a essa existência aurática da obra de arte, não deixa de vincular a esta função ritual. O valor único da obra de arte autêntica é sempre teologicamente fundado (PALHARES, 2006, 56)
\end{abstract}

No período de transição da sociedade feudal para o período burguês, ocorre a modificação da aura. O valor de culto, oriundo da apreciação do belo na arte, foi destruído, em favor de uma maior exposição do conteúdo artístico. Benjamin esboça um histórico da obra de arte e o seu relacionamento com o produtor e o consumidor desde a Idade Média até os nossos dias. (FREITAG, 2004, 74) À medida que as

3 Segundo Benjamin: "Retirar o objeto de seu invólucro, destruir sua aura, é a característica de uma forma de percepção, cuja capacidade de captar "o semelhante no mundo" é tão aguda que graças a reprodução ela consegue captá-lo até no fenômeno único". Cf. BENJAMIN, Walter, $A$ obra de arte na era de sua reprodutibilidade técnica, Obras Escolhidas Magia, técnica, arte e política. Vol. I p.170.

Professor de Filosofia do ensino básico nos Colégio Teleyos e Colégio Ateneu. Brasileiro, residente em Fortaleza - CE. Email: pablo tahim@hotmail.com 
obras de arte se emancipam do seu uso ritual, aumentam as ocasiões para que elas sejam expostas (BENJAMIN, 1985, 172).

Para Benjamin está explícito que a obra de arte em sua função ritualística possui, desde a antiguidade, um valor de contemplação e divinização perpetuado na tradição. Percebe-se, ao longo do tempo, até a Modernidade, a existência de uma tradição religiosa que envolve uma obra de arte, porém, algo não se perde, apenas modifica-se. A aura perpetua-se na fundamentação teológica, representando os deuses e seus heróis, até o período medieval, onde se visualiza ambientes divinizados, com estátuas representando anjos e santos. Nessa valoração, o conteúdo artístico está envolto de um caráter de unicidade que busca preservar o caráter autônomo de autenticidade da arte.

\begin{abstract}
Uma antiga estátua de Vênus, por exemplo, estava inscrita numa certa tradição entre os gregos, que faziam dela um objeto de culto, e em outra tradição, na Idade Média, quando os doutores da igreja viam nela um malfazejo. O que era comum às duas tradições, contudo, era a unicidade da obra ou, em outras palavras, sua aura. [...] O que é de importância decisiva, é que esse modo de ser aurático da obra de arte nunca se destaca completamente de sua função ritual. Em outras palavras: o valor único da obra de arte "autêntica" sempre tem um fundamento teológico, por mais remoto que seja: ele pode ser reconhecido, como ritual secularizado, mesmo nas formas mais profanas do culto ao belo (BENJAMIN, 1985, 171).
\end{abstract}

Benjamim denominará isto de hic et nunc, o aqui e agora da obra de arte. É a expressão da arte em manter uma unicidade, um selo de verdade, a manutenção do seu caráter de originalidade que não se perde sob nenhuma hipótese. É a sensação de estar diante de uma obra e sentir a existência única da tradição, uma forma de experiência vivenciada através dos tempos e que somente poderia ser experimentado em um instante, e persiste somente na contemplação do conteúdo original. Trata-se daquilo que conserva a história da obra, pois o aqui e agora constitui o conteúdo de sua autenticidade e nela se enraíza uma tradição que se identifica nesse objeto, até os nossos dias, como sendo aquele objeto sempre igual e idêntico a si mesmo (BENJAMIN, 1985, 167). Para Benjamin, a reprodutibilidade técnica vem destituir esse caráter de unicidade na obra artística, pois a sua esfera da autenticidade, como um todo, escapa à reprodutibilidade técnica, e naturalmente não apenas à técnica. (BENJAMIN, 1985, 167). O caráter de autenticidade da obra 
artística se perde ao se confrontar com as novas possibilidades de técnicas de reprodução.

As fotografias, na forma de retratos, buscaram a conservação de um sentimento de saudade, que remetiam a um passado feliz ou infeliz. A aura acena pela última vez na expressão fugaz de um rosto, nas antigas fotos (BENJAMIN, 1985,174). O grande momento da fotografia, quando ela irá definitivamente quebrar esta magia - o caráter aurático - será o momento em que o homem não participará mais das fotografias, ou quando o homem se torna um ser anônimo, um transeunte. Tal questão justifica a valorização benjaminiana da fotografia de Eugéne Atget, pois ele, ao iniciar o processo de radicalização fotográfica, ao registrar apenas as ruas desertas e imagens da cidade, e a retirada da figura humana da fotografia, o valor de exposição supera pela primeira vez o valor de culto(BENJAMIN, 1985, 174). No entender de Benjamin, essa transformação é importante, pois atesta uma ruptura histórica do distanciamento entre a arte e público e, ao mesmo tempo, uma aproximação da arte junto às massas, ocorrendo à liquidação do valor tradicional do patrimônio da cultura (BENJAMIN, 1984, 169). Com a evolução das técnicas de reprodução, o hic et nunc na obra de arte entra em declínio, pois a fotografia e o cinema são os principais protagonistas desse processo de 'desauratização' do conteúdo artístico. Neles, o aqui e agora da obra artística é atingido no seu cerne e efetiva-se o processo de destruição da aura na obra de arte ${ }^{4}$.

\section{Vestígios e aura: o contraste entre alegoria e símbolo}

Ao iniciar o capítulo Alegoria e Drama barroco na obra Origem do Drama Barroco Alemão, Benjamin realiza um percurso histórico sobre o fenômeno da construção estética dos conceitos de símbolo e alegoria, desde o classicismo até sua transformação, no drama barroco alemão, no século XVII. Com isso, ele objetivava uma compreensão do desenvolvimento histórico da mentalidade que se manifestava nesse tipo de expressão estética. Benjamin se apropriara de inúmeras técnicas da vanguarda, ou seja, elementos que compunham uma novidade artística

\footnotetext{
4 A partir do momento em que há uma aproximação do público com o conteúdo artístico outrora intocável a partir da reprodutibilidade técnica, o aqui e agora da arte, o aspecto presencial e imediato da arte é quebrado. Nesse sentido, ver: BENJAMIN, Walter, $A$ obra de arte na era de sua reprodutibilidade técnica, Obras Escolhidas Magia, técnica, arte e política. Vol. I, 1985, p. 167-168

Professor de Filosofia do ensino básico nos Colégio Teleyos e Colégio Ateneu. Brasileiro, residente em Fortaleza - CE. Email: pablo tahim@hotmail.com
} 
- como foi a poesia de Baudelaire. Em um meio acadêmico conservador, era esperada uma execração de tal trabalho ${ }^{5}$. Ao se dedicar a examinar a questão da alegoria e do símbolo no Barroco do século XVII, Benjamin observa que o conceito de símbolo se insere na esfera teológica, ali se impondo o seu contraste com a alegoria. O simbólico da alegoria se esvanece, quando se atinge a luz da teologia ${ }^{6}$.

A alegoria, como demonstra a obra benjaminiana, encontra-se interligada com a linguagem. Para Benjamin, o estudo alegórico, por meio dos hieróglifos da Modernidade, constata a busca por uma reprodução de ideias divinas. Valendo-se desse pressuposto, ele exemplifica com a escrita egípcia, demonstrando haver uma ligação do conceito moderno de alegoria com um caráter divino, sacral, em um aspecto especulativo e teológico.(BENJAMIN, 1984, 193). A alegoria, portanto, poderia ser considerada como uma forma de invalidar a convenção da tradição. Além de reagir ao desaparecimento da aura, a alegoria condensaria toda a história do sofrimento do homem, no mundo gerido pela ideologia, pois ela compreende a complexidade de sentidos capaz de exterminar de uma vez por todas com o pensamento unilateral. Nesse sentido, ele escreve:

\begin{abstract}
A escrita alfabética, enquanto combinação de átomos gráficos, está mais afastada que qualquer outra dessa escrita sagrada. É nos hieróglifos que esta se manifesta. $O$ desejo de assegurar o caráter sagrado da escrita - 0 conflito entre a validade sagrada e a inteligibilidade profana está sempre presente - impele essa escrita a complexos de sinais, a hieróglifos. É o que se passa com o Barroco. Externamente e estilisticamente - na contundência das formas tipográficas como no exagero das metáforas - a palavra escrita tende à expressão visual (BENJAMIN, 1984, 196-197).
\end{abstract}

Portanto, há uma busca da compreensão nessa relação entre alegoria e símbolo na história, pois a alegoria engloba o símbolo, transcendendo-o. (KOTHE,

5 Sobre o mosaico de citações, Kothe argumenta: "A construção do referido livro se baseia no princípio do mosaico: assim como ele é constituído por centenas e centenas de pastilhas díspares, cada qual com sua coloração que dará sentido a uma totalidade, a qual, por sua vez, mostrará o porquê da coloração de cada uma assim também este ensaio é constituído por centenas de citações. Estas são filtradas e posicionadas no sentido de sugerir a alegoria como figura básica ao entendimento do drama barroco. Depois se vê que a alegoria transcende as dimensões do próprio drama barroco. Esse texto é, portanto, fruto da absorção e transformação de outros textos, dos quais ele é o duplo." Cf. KOTHE, Flávio René. Para ler Benjamin, p. 26.

6 Para Benjamin: "Não é por acaso que o objeto desse exame é um torso. Na esfera da intenção alegórica, a imagem é fragmento, ruina. Sua beleza simbólica se evapora, quando tocada pelo clarão do saber divino. O falso brilho da totalidade se extingue." Cf. BENJAMIN, Walter. A Origem do Drama Barroco Alemão [1924]. Trad. br. Sergio Paulo Rouanet, São Paulo, Brasiliense, 1984, p.198.

Professor de Filosofia do ensino básico nos Colégio Teleyos e Colégio Ateneu. Brasileiro, residente em Fortaleza - CE. Email: pablo tahim@hotmail.com 
1976, 35). A tarefa que o Barroco exerce sobre o símbolo, é de conferir a alegoria, aquela tarefa de "dizer o outro", aquilo que the foi usurpado pelo símbolo nos períodos do Classicismo e no Romantismo. A questão alegórica em Benjamin busca também expressar uma ruína no sentimento melancólico do Barroco, aquilo que o símbolo não exteriorizava, ou seja, mostrar o que poderia ter sido e não foi. Segundo René Kothe:

"L'ecriture allégorique signifie toujours son Autre, le non-être de ce qu'elle représente". E é este outro que a alegoria revela e esconde, desvela e vela, que Benjamin vai querer decifrar: a visão de história como história do sofrimento dos homens (KOTHE, 1978, 63).

Pode-se apropriar, portanto, de uma perspectiva histórica enfatizada pela alegoria, assim como no quadro Melancolia I/ de Dührer, é retomada a questão do Angelus Novus. Benjamin mostra 0 anjo novo, o anjo satânico da história, que possui a sua fronte voltada para o passado em ruínas, de onde vem uma tempestade chamada progresso (Fortschritt) e por mais que o anjo tente voltar, com o objetivo de reconstruir o passado, ele é impedido. Ali também há uma perspectiva alegórica na análise benjaminiana - uma intenção de reconstituir a história assimilando na sua essência o ponto de vista dos vencidos, assim como está exposto no texto Sobre o Conceito de História (BENJAMIN, 1985, 226). Pode-se reconhecer em Benjamin algo de anti-reacionário, ao notar, no sentido mais amplo de sua visão histórica, que a alegoria, em nenhum momento, deveria servir aos propósitos burgueses. Segundo escreve Kothe:

\footnotetext{
Benjamin examina a estética clássica barroca e romântica para verificar que a alegoria nunca foi muito valorizada nem compreendeu, apesar dos grandes pintores, por exemplo, terem dedicado seus esforços as suas representações alegóricas [...]. A visão de história que ela representa não se adéqua aos interesses das classes dominantes, pelo menos na interpretação de Benjamin (KOTHE, 1978, 62).
}

O conceito de alegoria viria a ser aquilo que Benjamin, mais tarde, anunciaria na Pequena história da fotografia e na Obra de arte na era de sua reprodutibilidade técnica, ao abordar a questão da aura na obra de arte. Alegoria e aura, ambas se apresentam como uma 'aparição única de algo longínquo'. A alegoria se expressa na sua função primordial de "dizer o outro" (KOTHE, 1976, 43), ou seja, a 
aproximação de algo que se mantém distante. Porém, essa forma de 'representação' [Darstellung] do outro, entre esses dois conceitos benjaminianos, possui um caráter distinto. Se, de um lado, a alegoria demonstra aquele outro reprimido em sua melancolia dentro da história, de outro, a aura se impõe em uma função de superioridade: naquilo que ela possui de caráter sacral, em uma falsa função de proximidade. De acordo com Kothe:

\begin{abstract}
O "outro" aurático é inacessível e procura impor sua impossibilidade como condição de conformidade; o outro alegórico afirma sua possibilidade de existência desse mesmo outro. Luta pela negação deste outro enquanto apenas um "outro" afirmando-o. Esta afirmação enquanto primeira possibilidade de ser expresso é o passo inicial de sua própria negação (KOTHE, 1976, 38).
\end{abstract}

\title{
3. O cinema e a sua combinação de elementos: abordagem benjaminiana
}

O cinema traz uma reestruturação do problema que a fotografia atravessava. A experiência do cinema, já havia sido retratada inicialmente por Benjamin no final da década de vinte, em sua viagem à Moscou. Ali, Benjamin relata sobre a possibilidade de uma reutilização do cinema, que ele via como uma ferramenta de dominação burguesa. Ele retrata, a partir dessa percepção, a possibilidade de uma 'expropriação' do cinema, para uma finalidade revolucionária.(BENJAMIN, 1989, 69). Nesse momento, Benjamin já tivera contato com o cinema americano, a saber, o cinema político de Charles Chaplin.

Valendo-se desse pressuposto, no Diário de Moscou e em ensaios relacionados ao cinema russo, apesar de atestar ainda a precariedade material em sua composição, Benjamin observou sua perspectiva educadora voltada para fins da revolução. No seu ensaio Sobre a atual situação do cinema russo, Benjamin sustenta que o cinema russo apresentava um caráter educativo, onde a principal função era levar aos locais mais longínquos da Rússia pós-revolução, os propósitos revolucionários educativos com seus fins dentro da cultura (BENJAMIN, 2008, 325). Benjamin sustenta que:

Tendo muitas vezes observou que cenas sérias provocar o riso barulhento e que as cenas engraçadas são recebidas com rostos retos ou emoção mesmo genuína, cineastas começaram a produzir filmes diretamente para os cinemas viajam que ocasionalmente penetrar até as regiões mais remotas da Rússia para o benefício das pessoas que já viram nem cidades,

Professor de Filosofia do ensino básico nos Colégio Teleyos e Colégio Ateneu. Brasileiro, residente em Fortaleza - CE. Email: pablo tahim@hotmail.com 
nem meios modernos de transportar. Para expor essas plateias para o cinema e rádio constitui um dos experimentos em massa psicológicos mais grandiosos já realizados em laboratório gigantesco que a Rússia se tornou. Escusado será dizer que, em tais cinemas rurais, o papel principal é interpretado por filmes educativos de todo tipo. Esses filmes vão desde aulas de como lidar com pragas de gafanhotos ou usar tratores, para filmes preocupados com a cura para o alcoolismo ${ }^{7}$.

A respeito da técnica, Benjamin no ensaio $A$ Obra de arte na era de sua reprodutibilidade técnica, retoma a defesa da técnica reprodutiva de massa do cinema como uma forma de politização das massas. Para tanto Benjamin expõe uma série de elementos que poderiam contribuir para reforçar o potencial da técnica cinematográfica, como ferramenta de reflexão, em meio as constantes mudanças de ordem cultural e política. Além disso, ele elucida certas diferenças entre o teatro e o cinema, a saber, as diferenças em ralação à postura do ator. O cinema possui um caráter diferenciado, pois há uma exigência de perfeição na postura do ator perante a câmera. A possibilidade de uma mesma cena ser gravada por mais de uma vez, não exige do ator uma necessidade de ser um 'profissional' como no teatro, Segundo sustenta Benjamin:

\begin{abstract}
Pois nada contrasta mais radicalmente com a obra de arte sujeita ao processo de reprodução técnica (...). A exemplo do cinema que a obra teatral, sempre nova e originária do ator. (...) Desde muito, os observadores especializados reconheceram que "os maiores efeitos são alcançados quando os atores representam o menos possível". (...) Há uma outra circunstância correlata: $\mathrm{O}$ ator de teatro, ao aparecer no palco, entra no interior de um papel. Sua atuação não é unitária, mas decompostas em várias cenas individuais cuja concretização é determinada por fatores puramente aleatórios como o aluguel de um estúdio, disponibilidade de outros atores, etc. (BENJAMIN, 1985, 181).
\end{abstract}

Tal questão demonstra, portanto, que Benjamin identifica no cinema uma quebra definitiva do valor cultual da obra de arte. Além da mudança da postura do ator perante a máquina, com base na representação do cotidiano coletivo, o cinema

7 Para Benjamin: "Having often noted that serious scenes provoke uproarious laughter and that funny scenes are greeted with straight faces or even genuine emotion, filmmakers have started to produce films directly for those traveling cinemas that occasionally penetrate even the remotest regions of Russia for the benefit of people who have seen neither towns nor modern means of transport. To expose such audiences to film and radio constitutes one of the most grandiose masspsychological experiments ever undertaken in the gigantic laboratory that Russia has become. Needless to say, in such rural cinemas the main role is played by educational films of every kind. Such films range from lessons in how to deal with plagues of locusts or use tractors, to films concerned with cures for alcoholism. Cf. BENJAMIN, Walter. The Work of Art and Other Writings on Media. p.323.

Professor de Filosofia do ensino básico nos Colégio Teleyos e Colégio Ateneu. Brasileiro, residente em Fortaleza - CE. Email: pablo tahim@hotmail.com 
aproximaria as pessoas da realidade e daí ocorreria um processo de politização. A maior difusão da exibição dos filmes veio também por uma necessidade econômica, pois as produções de filmes eram muito caras. Com isso, fazia-se necessário a exibição dos filmes para milhares de pessoas, várias vezes, a fim de se repor os gastos. Um exemplo são os nickelodeons ${ }^{8}$, locais onde os filmes eram exibidos em massa no valor de um níquel. Essa forma de exibição tinha uma importância social.

Afirma-se que as massas procuram a distração na obra de arte, ao passo que o conhecedor a aborda com recolhimento. Para as massas, a obra de arte seria objeto de diversão, para o conhecedor objeto de devoção (BENJAMIN, 1985, 192). Aqui pode-se remeter à questão da distração (Unterhaltung) ${ }^{9}$ exposto por Benjamin em seus ensaios sobre o rádio. Em relação ao cinema, Benjamin considera que o cinema possuía um caráter importante, pois seria uma ferramenta com possibilidade para a crítica das massas ${ }^{10}$.

Com o cinema, a aura recebe um golpe fulminante, ao passo que a técnica alcançou o ápice do seu desenvolvimento. A partir deste momento, Benjamin percebe a possibilidade de democratização e acessibilidade ao conteúdo artístico mediante uma serie de fatores. Benjamim sustenta a existência de uma refuncionalização da arte no cinema, onde finalmente a técnica se emancipa de qualquer influencia ritual. A partir de agora, a técnica de reprodução sob a forma do cinema conseguia alcançar o grande público.

\section{Estética e universo político: ruína da aura e da Estética tradicional}

8 Segundo Fernando Mascarello: "Os nickelodeons surgem a partir de 1905, quando muitos empresários de diversões começam a utilizar espaços bem maiores que os vaudeviles para a exibição exclusiva de filmes.[...] esses novos ambientes eram, em geral, grandes depósitos ou armazéns adaptados para exibir filmes para o maior número possível de pessoas, em geral trabalhadores de poucos recursos. [...] Mas ali se oferecia a diversão mais barata do momento: 0 ingresso custava cinco centavos de dólar - ou um níquel, daí seu nome." Cf. MASCARELLO, Fernando. História do Cinema Mundial. Coleção Campo Imagético, São Paulo: Papirus., 2006, p. 26.

9 O termo Unterhaltung, remonta a questão do caráter de entretenimento, quando Benjamin discorre a respeito dos efeitos do rádio e do teatro épico sobre as massas, onde através deste, conseguirse-ia alcançar o interesse do povo para uma interpretação crítica.

${ }^{10}$ Benjamin busca estabelecer um paralelo com o Dadaísmo no que diz respeito a questão da distração. Conforme seus argumentos, o cinema buscou os mesmos princípios do choque na ação contemplativa como fundamental para destituí-la de uma apropriação mercadológica. Nesse sentido ver: Cf. BENJAMIN, Walter. A obra de arte na era de sua reprodutibilidade técnica. Obras Escolhidas Vol. I Magia e técnica, Arte e política, p.191.

Professor de Filosofia do ensino básico nos Colégio Teleyos e Colégio Ateneu. Brasileiro, residente em Fortaleza - CE. Email: pablo tahim@hotmail.com 
Retornando ao caráter alegórico da obra de arte, a aura artística assume a sua ruína destrutiva na poesia de Baudelaire, em decorrência das modificações sociais da Modernidade, oriundas da crescente industrialização e modernização, que possuem a consequência inevitável da destruição da aura. As dicotomias vivenciadas por Baudelaire entre as várias conjunturas políticas na Paris do século $\mathrm{XIX}$, as suas mudanças de postura perante as circunstâncias de vida, demonstram ali, uma inconsistência, não somente do autor, mas também da arte naquele período de constante transformação política e cultural na Europa (KOTHE, 1978, 83-84)

Além disso, na Modernidade, o homem coletivo passa a vivenciar a vida do homem privado. Para Benjamin, o mundo privado do homem é o seu interieur. A partir de então, o homem precisa de um espaço próprio para poder fomentar as suas ilusões, para nutrir a fantasmagoria do mundo que o cerca. Em Benjamin, o interieur seria uma espécie de local intocável, onde o homem vivenciaria o seu individualismo. Daí ele escrever:

\footnotetext{
O homem privado, que no escritório presta contas a realidade, exige que 0 interieur sustente em suas ilusões. [...] na configuração de seu mundo privado, reprime ambas. Este representa para o homem privado o universo. Aí ele reúne o longínquo e o passado. Seu salão é um camarote para o teatro do mundo. (BENJAMIN, 2006, 45)
}

Benjamin observa no interiéur, uma forma de manutenção da aura na arte. A princípio, Benjamin revela o interieur como uma nova forma de estilo de vida na Modernidade, onde o homem se torna recluso em sua individualidade. Ali então, ele alia a imagem do interiéur com a do colecionador, aquele que habita o interieur e mantém também recluso o objeto artístico. Benjamin apresenta essa atitude do colecionador como a forma em que ele buscou destituir da arte a sua função mercadológica e acabou fazendo com que a arte se 'refugiasse' na vida privada (BENJAMIN, 2006, 46).

No ensaio $A$ obra de arte na era de sua reprodutibilidade técnica, Benjamin busca fundamentar teorias com o objetivo de se contrapor com a atual apropriação do fascismo sobre a nova técnica de reprodução. Segundo Benjamin, as técnicas de reprodução sobre a arte estariam sendo reapropriadas em função da ideologia fascista. Em meio à ascensão de regimes totalitários e a consequente derrota das forças de esquerda na Europa, Benjamin observa que a fetichização da cultura 
ocorrerá a partir do momento em que o fascismo se apropriara do cinema como instrumento de propaganda ideológica para as massas. A técnica de reprodução mostra-se, portanto, como um artífice para o fascismo. Tal apropriação da técnica, e a atribuição de valores nacionalistas em uma sociedade alemã marcada pela guerra, se apresentavam como forma de recuperação do orgulho alemão. De acordo com Taísa: Palhares:

Benjamin é apontado como um dos únicos pensadores a perceber que para os intelectuais de direita na Alemanha, a desvinculação da técnica dos ideais de republica era sinônima de recuperação da alma alemã, e que a revolta contra a racionalização assumia a forma de culto da técnica ( PALHARES, 2006, 46).

Benjamim observa que o fascismo buscava uma salvação para a anulação das massas nas atuais relações de produção baseadas na exploração do homem pelo homem. Para tanto, o fascismo se apropriou da técnica, promovendo a sensação de uma libertação falseada para os homens. Em sessões cinematográficas da época, o expectador fazia então parte da imagem, ou seja, sentia-se parte de um todo, o que Benjamin chama de 'reprodução das massas', possibilitando às massas verem o seu próprio rosto. Esse modo de 'expressão da natureza' não significava, porém, que o proletariado tivesse os seus direitos resguardados. Algo semelhante, Benjamin visualizava na obra de Baudelaire a respeito das multidões apressadas na sociedade moderna. Pode-se inferir que ali havia também uma massa estandartizada, que se encontrava perdida em uma fantasmagoria fetichizada (KOTHE, 1978, 100).

Georg Simmel, pensador do final do século XIX e inicio do século XX, possui um ensaio denominado As grandes cidades e a vida do espírito (1900). Simmel faz um diagnóstico sobre o problema da vida do homem moderno nas cidades e como essas mutações alteraram o estilo de vida do homem. Simmel alega que em virtude do novo modo de produção, os homens estariam se perpetuando em sua própria individualidade. A sociedade, com o passar dos tempos, sofreu uma serie de mutações, que tiraram o homem de uma ambientação baseada em relações sociais que o mantinham diante de certa coletividade e o levaram a uma situação de individualidade que por si só é tão alienadora, que mostra a existência de uma perpetuação de um espírito objetivo em detrimento de um espírito subjetivo. 
Benjamin dará razão a Simmel. Ele observa o fenômeno da integração do homem na multidão uniformizada e amorfa, e sobretudo, os problemas que isso estaria acarretando como a perda da experiência coletiva. Simmel denomina isso de "carácter blasé". De acordo com Simmel:

\begin{abstract}
Talvez não haja nenhum fenômeno anímico, que esteja reservado de modo tão incondicional à grande cidade, como o carácter blasé. Ele é, de início, a consequência daqueles estímulos nervosos, que com rapidez se alteram e se condensam nos seus antagonismos, dos quais nos parece provir também a intensificação da intelectualidade na grande cidade; justamente por isso, homens broncos e de antemão sem vida espiritual não costumam ser blasés. Assim como uma vida imoderada de prazeres torna blasé, porque excita por muito tempo os nervos nas suas reações mais fortes, até que eles acabam por já não ter nenhuma reação, assim também as impressões inofensivas, pela rapidez e pela incompatibilidade da sua mudança, forçam os nervos a respostas tão violentas, irrompem para cá e para lá de modo tão brutal, que eles entregam a sua última reserva de forças e, permanecendo no mesmo meio, já não têm tempo para acumular uma nova (SIMMEL, 2009, 08).
\end{abstract}

O caráter blasé, denominado por Simmel, remonta ao pensamento constituído por Benjamin cerca de trinta anos depois, no ensaio Experiência e Pobreza e em $O$ Narrador. O caráter blasé é exatamente esta ausência de experiência que na Modernidade se encontra em vias de extinção. Benjamin retrata que os homens atravessavam um período de ausência de experiências de vida, por causa da experiência da guerra, onde os homens já não possuíam mais estórias para contar e repassar aos seus descendentes. O mesmo pode ser considerado a respeito do blasé da vida citadina, onde os homens, ao incorporar ao máximo os elementos da Modernidade, abandonam e não se permitem receber novas experiências, tornandose indiferentes a qualquer modificação interior ${ }^{11}$.

As semelhanças entre Simmel e Benjamin não se reduzem apenas a essa questão. Ao retratar o aspecto das populações nas cidades e como as mesmas reagem à Modernidade, é identificada a mesma percepção em relação à multidão, calcada em elementos que remontam aos problemas do mercado e do avanço do

\footnotetext{
${ }^{11}$ Simmel estabelece uma diferenciação entre os aspectos sociais na Modernidade, mostrando como a sociedade modificou os seus hábitos no após a Revolução Industrial. Daí ele se reportar ao caráter individualista da vida anímica nas grandes cidades, baseado num objetivismo, e a vida que era baseada em relações pautadas pelo sentimento da vidas nas pequenas cidades. Ver nesse sentido: SIMMEL, Georg A Vida das Grandes Cidades e a Vida do Espírito. p.04.
}

Professor de Filosofia do ensino básico nos Colégio Teleyos e Colégio Ateneu. Brasileiro, residente em Fortaleza - CE. Email: pablo tahim@hotmail.com 
capitalismo, que alterou as formas e a relação de vivência da população entre $\mathrm{si}^{12}$. Assim como Simmel, Benjamin faz uma crítica ao modo de produção capitalista e como ele transformou as grandes massas em um bloco amorfo, mas imerso em sua própria interioridade. As multidões, tão analisadas por Benjamin, em especial, na obra das Passagens, mas, sobretudo em outros ensaios dedicados à obra de Baudelaire, representam o exemplo da Modernidade em seu caos. O flaneur personagem de uma poesia de Baudelaire - inebriado pela fantasmagoria da grande cidade, com suas galerias e lojas de novidades, já não se reconhece como classe social, o que representa o próprio Baudelaire como a incorporação deste dândi moderno.

\section{Considerações Finais}

Portanto, este processo de não reconhecimento das massas em sua própria alienação em meio às contradições da Modernidade e do universo burguês com suas contradições, a quebra de um sentimento de necessidade de um laço de experiência histórica, se põem como uma abertura para uma apropriação fascista do conteúdo artístico. A absorção da arte pelo capitalismo, a manutenção de valores cultuais na arte, o sentimento conservador de manter os valores da tradição burguesa constituem a própria conservação da l'art pour art. Em sua função estética, o fascismo reforçava o seu caráter ideológico, utilizando-se também dos movimentos culturais, como o futurismo, que se mostravam favoráveis ao enaltecimento de elementos da técnica que favoreceriam a manutenção do status quo. Percebe-se, portanto, que o uso da tecnologia, tão defendida por Benjamin, também poderia assumir um caráter destruidor: daí a constatação do problema da situação da arte em meio ao momento político estabelecido. Por conseguinte, ou a arte se põe no reduto da l'art pour art $^{13}$, onde ali, se apresentava como uma forma de resguardar

\footnotetext{
${ }^{12}$ Segundo Simmel, "De facto, a reserva e a indiferença mútua, as condições espirituais da vida dos círculos mais vastos, nunca foram sentidas de modo mais forte, no seu efeito para a independência do indivíduo, do que na turba mais compacta da grande cidade, porque o aperto e a proximidade corporal é que tornam verdadeiramente explícita a distancia espiritual; e, claro está, é apenas o reverso desta liberdade se, sob certas circunstancias, em nenhum lugar alguém se sente tão solitário e abandonado como justamente na multidão da grande cidade; pois aqui, não é necessário que a liberdade do homem se espalhe na sua vida emotiva como bem estar.Cf. SIMMEL, Georg $A$ Vida das Grandes Cidades e a Vida do Espírito. p.14.

${ }^{13}$ Segundo KOTHE, "Segundo Adorno, a "arte pela arte" também precisa ser salva, apesar da frente ampla contra ela. (...) Declara que não pretende assegurar a autonomia da arte como uma reserva

Professor de Filosofia do ensino básico nos Colégio Teleyos e Colégio Ateneu. Brasileiro, residente em Fortaleza - CE. Email: pablo tahim@hotmail.com
} 
ainda a única chance da humanidade de uma promesse de bonheur, ou então oferece uma perspectiva, onde a arte em si não estivesse interligada aos meios de produção.

A arte em si deveria possuir uma função de melhorar as condições de vida do homem em geral. A utilização da função estética pelo fascismo representa, no entanto, a inversão desses valores (KOTHE, 1976, 92). Dai a importância do surgimento dos movimentos surrealista e dadaísta, na análise da possibilidade relativa ao fim da arte. Benjamin obsevava a possibilidade de transcendência da própria arte. O seu fim poderia também ser o seu recomeço. Segundo expõe Kothe:

Para Benjamin, a força revolucionária do Dadaísmo e do Surrealismo estavam na capacidade de questionar a legitimidade da própria arte. Ambos os movimentos impuseram a questão de saber se - à medida que a arte é mancomunada com a cultura e a sociedade existentes - não seria a verdadeira e radical tarefa dos artistas engajados acabar com a própria arte ou então abandoná-la (KOTHE, 1976, 68).

Em O autor como produtor (1934), Benjamin elabora uma crítica ao romance burguês, no sentido de demonstrar que os romances que eram produzidos naquele momento atendiam aos interesses da classe burguesa, ou seja, a manutenção do status quo. Há uma defesa em Benjamin, a saber, da produção de uma literatura que trabalhasse em prol da revolução ${ }^{14}$ e contra esse status quo, por meio de obras que atendessem à realidade do proletariado e o transformasse em um agente crítico-reflexivo. Isso justifica a sua defesa da obra de Brecht: algo fundamental para a compreensão dessa revolução literária almejada por Benjamin. Brecht seria a contraposição do intelectual, que possuía uma produção em forma de práxis política, diferentemente do que ocorria com outros escritores.

Há de se considerar as seguintes indagações em conformidade com Benjamin: qual a situação do escritor que produz em meio ao caos do fascismo? De uma literatura que legitima tal sistema social? De uma literatura que estabeleça uma

(Reservat); concorda com o fato do aurático estar desaparecendo, e isto não só pela reprodutibilidade técnica, mas, acima de tudo, pelo próprio desenvolvimento da lei autônoma da arte." Ver nesse sentido, KOTHE, Flávio René, Benjamin e Adorno: confrontos. pag. 44.

14 Diante do plano desta arte refuncionalizada, Benjamin adiantara a respeito no ensaio $O$ Surrealismo, ultimo instantâneo da inteligência europeia (1929) sobre a ausência de um compromisso ideológico e o problema da necessidade de uma arte que fosse voltada para um sentido revolucionário. Ver nesse sentido: BENJAMIN, Walter O surrealismo, ultimo instantâneo da inteligência européia In: Obras Escolhidas I, Magia Técnica Arte e Política, p. 29

Professor de Filosofia do ensino básico nos Colégio Teleyos e Colégio Ateneu. Brasileiro, residente em Fortaleza - CE. Email: pablo tahim@hotmail.com 
crítica, mas que se encontra destituída de práxis? Ou de uma literatura que estabeleça princípios que levem para além de uma atitude critico-reflexiva, orientada para uma práxis, ou seja, uma ação efetiva para a revolução? Para Benjamin, a técnica estaria passível de ser utilizada para quaisquer outros fins, seja de ordem revolucionária, seja reacionária. Disso resulta a sua crítica ao 'Ativismo' e à 'Nova Objetividade', que velava um objetivo reacionário, pois permanecia uma ação calcada apenas em um discurso, sem nenhum tipo de proposição que conduzisse a uma ação direta revolucionária, mas se revelava estéril de propósito. Dai a leitura feita por Benjamin, na sua defesa de Brecht sobre uma arte refuncionalizada, que respondesse aos anseios das massas oprimidas. Segundo escreve Benjamin:

\begin{abstract}
Brecht criou o conceito de refuncionalização para caracterizar as formas e instrumentos de produção por uma inteligência progressista e portanto, interessada na liberação dos meios de produção a serviço da luta de classes. Brecht foi o primeiro a confrontar o intelectual com a exigência fundamental: não abastecer o aparelho de produção sem modifica-lo na medida do possível, num sentido socialista (BENJAMIN, 1985, 127).
\end{abstract}

Nesse sentido, a questão da aura e a sua dissolução na obra de arte se põe como algo fundamental em Benjamin. A aura, não estaria presente somente nas pinturas, ou esculturas, mas em toda forma de arte que se põe ideologicamente como obstáculo no objetivo de um esclarecimento de uma determinada sociedade. $A$ aura é a manutenção de privilégios de uma determinada classe social em suas regalias. O que Benjamin propõe ao examinar a evolução da fotografia, do cinema, do teatro, bem como de movimentos de vanguarda como o Dadaísmo e o Surrealismo $^{15}$ é uma nova leitura estética ${ }^{16}$, em que a arte se ponha a favor de uma revolução, baseada na luta de classes, que a sociedade não se ponha contra as ruínas constituídas pela consciência histórica burguesa, mas que utilize a técnica a

\footnotetext{
${ }^{15}$ Segundo Benjamin, o surrealismo seria uma das formas da arte de vanguarda que mais se aproximaria de uma leitura comunista da arte. Ver nesse sentido: BENJAMIN, Walter $O$ surrealismo, ultimo instantâneo da inteligência européia In: Obras Escolhidas I, Magia Técnica Arte e Política, p. 35

${ }^{16}$ Segundo René Kothe: "E como Benjamin avaliou o surrealismo? - Ao contrário de Lukacs, aceitouo, porque, sendo um rompimento interno com a estética tradicional, também rompia com o modo de vida e de pensamento a que estava ligada. $O$ demonismo dos surrealistas, a sua afirmação do mal. É uma negação imanente do modo de ser burguês. O espírito de liberdade radical levou-os a politização e à esquerda, contra as limitações da ordem existente, e a história de sua evolução se caracteriza pela superação do anarquismo inicial (...) O surrealismo foi um esforço de conquistar as forças de êxtase (Raush) para a revolução; em todo ato revolucionário, há um certo momento de êxtase anarquista". Cf. KOTHE, Flávio René. Benjamin e Adorno; Confrontos, p.85.
}

Professor de Filosofia do ensino básico nos Colégio Teleyos e Colégio Ateneu. Brasileiro, residente em Fortaleza - CE. Email: pablo tahim@hotmail.com 
favor de um questionamento da legitimidade da própria arte (KOTHE, 1976, 88), da reflexão e da práxis política dos oprimidos, onde estes sejam sujeitos de uma transformação histórica da humanidade. 


\section{REFERÊNCIAS}

BENJAMIN, Walter. Obras Escolhidas I Magia e Técnica, Arte e Política. [1985] Trad. br. Sérgio Paulo Rouanet, São Paulo: Brasiliense, 2011. [Obras Escolhidas, vol. I].

Obras Escolhidas III Charles Baudelaire. Um lírico no auge do capitalismo. [1989]. Obras Escolhidas. Trad. br. Sérgio Paulo Rouanet, São Paulo: Brasiliense, 2011 [Obras Escolhidas, vol. III].

A Origem do Drama Barroco Alemão [1924]. Trad. br. Sergio Paulo Rouanet, São Paulo: Brasiliense, 1984

Diario de Moscou [1980] Trad. br Hildegard Herbold. São Paulo, Companhia das Letras 1989

2006.

Passagens. Trad. br. de Irene Aron. Belo Horizonte: Editora da UFMG,

The Work of Art and Other Writings on Media. Harvard University Press. Londres, 2008.

BAUDELAIRE, Charles. As Multidões In: Baudelaire Col. Gigantes da literatura universal Trad. Pt. Fernanda Botelho, Editorial Verbo, 1969

BUCK-MORSS, Susan Dialética do olhar: Walter Benjamin e o projeto das Passagens. [Trad. Ana Luiza Andrade], Ed. UFMG, Ed. Argos. Belo Horizonte 2002

DE CASTRO CALLADO, Tereza. "Confrontos na estética benjaminiana - arte simbólica versus arte alegórica" in:_Cadernos Walter Benjamin N. 11, no site www.gewebe.com.br, pp. 78-87.

"O drama da alegoria no século XVII barroco" in:

Kalagatos - Revista de Filosofia, Fortaleza: Eduece, 2004.

KOTHE, Flávio René. Benjamin e Adorno: Confrontos São Paulo; Ática; 1978.

Para ler Benjamin, Rio de Janeiro, Ed. Francisco Alves, 1976

MASCARELlO, Fernando. História do Cinema Mundial. Coleção Campo Imagético, Ed. Papirus. São Paulo, 2006

PALHARES Taísa Helena Pascale. Aura: a crise da arte em Walter Benjamin São Paulo, Barracuda, 2006.

SIMMEL, Georg A Vida das Grandes Cidades e a Vida do Espírito. [1903] Trad. pt Artur Mourão. Colecção Artigos LusoSofia, Universidade da Beira Interior, Covilhã, 2009 